\title{
Influencing factors research and performance experiment on droplets deposition at low wind speed
}

\author{
Suming Ding ${ }^{1}$, Xinyu Xue ${ }^{1 *}$, Weicai Qin ${ }^{1}$, Wei Gu${ }^{1}$, Chen Cai ${ }^{1}$, Longfei Cui ${ }^{1}$ \\ (Nanjing Research Institute of Agricultural Mechanization, Ministry of Agriculture, Nanjing 210014, China)
}

\begin{abstract}
In view of the droplet drift during aerial spraying, a droplet deposition distribution measurement system was designed to determine the droplet size under different spray pressures using LURMARK-04F80 nozzle. Wind tunnel was used to simulate the natural wind by generating fixed-speed wind. According to the international standard (ISO/FDIS 22856:2008), nozzle was installed at $0.6 \mathrm{~m}$ above the wind tunnel bottom. Deposition drift was assessed by adding fluorescent tracer to the spray mixture and measuring the quantities of droplet deposition on the PE Twines which were installed perpendicular to the wind direction in a vertical and a horizontal array. At $2 \mathrm{~m}$ distant from the static nozzle at downwind direction and $0.1 \mathrm{~m}$ above the wind tunnel bottom, five PE Twines are positioned vertically one above the other at interval of $0.1 \mathrm{~m}$ and seven PE Twines are positioned horizontally one above the other at interval of $1 \mathrm{~m}$. By analyzing the drift index at different positions, the influences of spray angle, nozzle angle, side wind and spray pressure on the droplet drift were studied. Experimental results show that drift index on the line decreases as vertical and/or horizontal distance increase. Spray pressure and wind speed have great influence on the drift parameter. Droplets drift still exists at $7 \mathrm{~m}$ distant from the nozzle when spray pressure attains $0.4 \mathrm{MPa}$. Wind speed attains $3 \mathrm{~m} / \mathrm{s}$ and spray angle is $0^{\circ}$ or wind speed attains $5 \mathrm{~m} / \mathrm{s}$. Spray pressure attains $0.3 \mathrm{MPa}$ and spray angle is $0^{\circ}$. The drift index in the vertical and the horizontal direction when the spray angle is $0^{\circ}$ is higher than that of the other spray angles. When spray distance attains $4 \mathrm{~m}$ and nozzle angle attains $0^{\circ}$, the drift index is higher than that of the other nozzle angles. To reduce the droplet drift when the wind speed attains $5 \mathrm{~m} / \mathrm{s}$, spray operation creating droplet size should be adopted and the spray angle should be adjusted. This study provides optimized operation parameter for aerial nozzle and plays a vital role in reducing droplet drift.
\end{abstract}

Keywords: wind tunnel, spray atomization, droplet deposition, drift index, nozzle, spray angle, nozzle angle DOI: $10.33440 /$ j.ijpaa.20190201.0017

Citation: Ding S M, Xue X Y, Qin W C, Gu W, Cai C, Cui L F. Influencing factors research and performance experiment on droplets deposition at low wind speed. Int J Precis Agric Aviat, 2019; 2(1): 46-51.

\section{Introduction}

Agricultural aerial spraying has been a significant means of crop diseases and pest control ${ }^{[1-3]}$. Ideally, deposit of pesticide will be in the area of target in an aerial spraying application. However, due to environmental conditions, the aerial applied droplets will drift to the non-target area ${ }^{[4-6]}$, which results in poor control effect, pesticide loss and environmental pollution ${ }^{[7-11]}$. Thus, pesticide spray drift control of aerial spraying application became a worldwide research hotspot.

Aerial spray drift is mainly influenced by spraying parameters (nozzle types, spray pressure, spray angle, droplet size, etc.) and application environment (wind speed, wind direction, temperature, flying speed, etc. $)^{[12-15]}$. Recent years, two major research

Received date: 2019-09-10 Accepted date: 2019-10-20

Biographies: Suming Ding, Senior Scientist, research interest: crop protection machinery and advanced pesticide application technology, Email: 465890551@ qq.com; Weicai Qin, Assistant Scientist, research interest: plant protection and pest control, Email: 278886580@qq.com; Gu Wei, Assistant Scientist ,research interest: the establishment of Standards for Technical Standards of Agricultural Aviation Drug Application, Email: phenykoo@foxmail.com; Cai Chen, Assistant Scientist, research interest: the design of basic components for pesticide application, Email: 814420600@qq.com; Cui Longfei, Assistant Scientist, research interest: the control method of spray boom suspension system, Email: cuilong.fei@163.com.

*Corresponding author: Xinyu Xue, PhD, Senior Scientist,, research interest: crop protection machinery and advanced pesticide application technology. Mailing address: Nanjing Research Institute for Agricultural Mechanization, Ministry of Agriculture Nanjing, NO.100 Liuying, Xuanwu District, Nanjing City, Jiangsu, 210014, China. Email: xuexynj@qq.com. methods were field and wind tunnel experiments. The repeatability of field experiments was bad due to the unstable wind speed and direction ${ }^{[16]}$. However, wind tunnel experiments can control the spraying parameters and application environment, and gain ideal repeatability ${ }^{[17,18]}$. The influences of spraying parameters and application environment upon the spray drift have been reported in many studies. Geng et al. ${ }^{[19]}$ researched the relationship between fan nozzles' height and drift potential index reduction percentage (DIXRP) by wind tunnel experiments. Teskel et al. ${ }^{[20,21]}$ developed the AGDISP (Agricultural Dispersion) and the AGDRIFT (Agricultural Drift) model to predict pesticide spray drift in a field experiment. Nuyttens et al. ${ }^{[22]}$ researched the spray drift prediction method at different spray pressures, nozzle types and flying speed. $\mathrm{Li}$ et al. ${ }^{[23]}$ investigated the ground deposition at different spray quantity and concentration based on mathematical model by using a spectrophotometer. Qi et al. ${ }^{[24]}$ examined the influence of different nozzle types and wind speed on the drift based on a quantitative analysis. Zhang et al. ${ }^{[25,26]}$ established regression analysis model of spray drift at different dosage forms, nozzle types and wind speed.

Fan nozzle is one of the major used nozzle types in the aerial spraying. Through literature review, there are few researches on spray drift of fan nozzles at different spray angle, nozzle angle, wind and spray pressure. Thus, we generated constant speed wind in a wind tunnel to simulate natural wind, and built a spray system to study droplets deposition of a fan nozzle in both horizontal and vertical directions in different work conditions. The work can provide a reference for future research on aerial spraying technology. 


\section{Experimental design and methods}

The experiment was carried out in the Key Laboratory of Modern Agricultural Equipment, Ministry of Agriculture, Nanjing, China in May 2017. Environment temperature was $22^{\circ} \mathrm{C}$, and relative humidity was $55 \%$.

\subsection{Droplet size distribution measurement}

Droplet size is a critical factor of pesticide drift and deposition. At the same spray quantity, the smaller the droplet size, the more the droplets will be, so the more evenly distributed and the more covered area will be in the target. Due to their own properties (low momentum, small particle size, easy evaporation), small droplets are influenced by environmental factors (temperature, humidity, wind speed). Some small droplets will fail to reach the target. In order to measure the effect of different droplet size on the drift performance, we built a testbed (Figure 1) that consists of spray system, DP-02 laser particle analyzer (measurement range: $1-1500 \mu \mathrm{m}$, temperature: $5-3^{\circ} \mathrm{C}$, relative humidity $<85 \%$ ), WT5002N electronic scale (measurement range: 0-500 g, accuracy: \pm 0.01 , made by Changzhou Wantai Scales Ltd., China), and etc. According to different working conditions, spray pressure was set to $0.2,0$, and $0.4 \mathrm{MPa}$, respectively. The droplet size and flow rate were measured at three pressures. The installed nozzle was

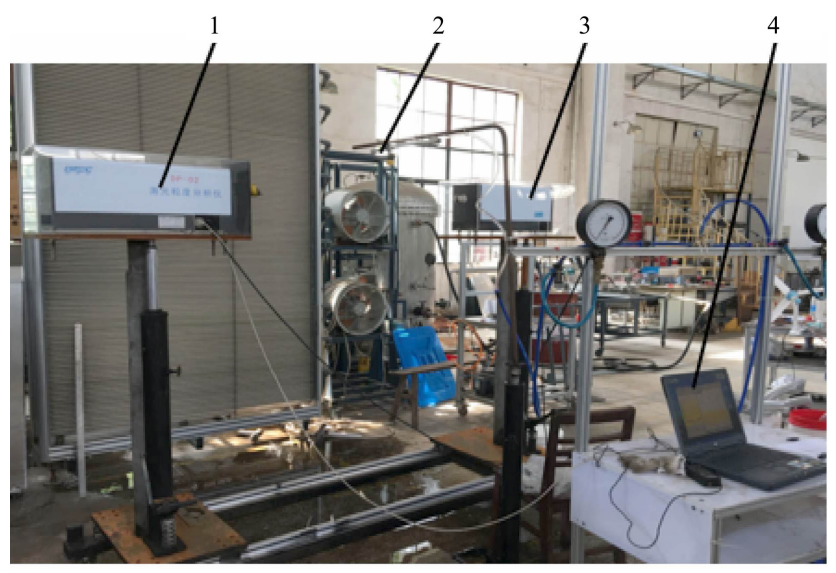

1. Laser particle sizing instrument emission unit 2. Nozzle 3. Laser particle sizing instrument acceptance unit 4. Computer processing system

Fig 1 Schematic diagram of droplet diameter test the LURMARK-04F80 standard fan nozzle. We started the spray system utill the spray pressure stabilizes, then started the laser particle analyzer, and adjusted the position of the nozzle and the analyzer to ensure the laser go straight through the spray sector. The distance between laser and nozzle was $500 \mathrm{~mm}$ to ensure that the entire spray area was sampled in the repeated measurements. Then, the spray flow rate was measured at different spray pressure, and the spray time was 60 seconds at each spray pressure. The collected droplets were weighed on the scale and the measurement repeat three times at each pressure.

\subsection{Spray deposition distribution measurement}

\subsubsection{Testbed}

The measurement system of spray deposition distribution consists of spray system, wind tunnel system and collection system. Spray system consists of motor, liquid pump, water tank, pressure gauge, spray pressure regulating valve, LURMARK-04F80 nozzle, solenoid valve, timing relay, etc. The wind tunnel is NJS-1 wind tunnel developed by Nanjing Research Institute of Agricultural Mechanization, Ministry of Agriculture ${ }^{[27]}$. By changing the frequency of the frequency converter to control the revolving speed of the axial flow fan in the wind tunnel, it can obtain different stable wind speed. Its test section size is $1.2 \mathrm{~m} \times 1.8 \mathrm{~m} \times 10 \mathrm{~m}$ (width $\times$ height $\times$ length) and adjustable range is $0.5-10 \mathrm{~m} / \mathrm{s}$. The collection system mainly consists of collection racks in different height and interval. The nozzle is fixed at the center position of $0.6 \mathrm{~m}$ height from the wind tunnel bottom, and the nozzle direction is vertically downward. The principle is that the spray long axis and wind direction are perpendicular to each other. The droplets are collected by PE Twines with a diameter of $2 \mathrm{~mm}$. In the downwind direction, at the position of $2 \mathrm{~m}$ from the nozzle, 5 collection lines with $0.1 \mathrm{~m}$ interval is placed between 0.1 and $0.5 \mathrm{~m}$ height from the wind tunnel bottom. The bottom was covered by artificial turf to avoid that droplets drop on the baseplate to splash to the collection lines. These collection lines are used to detect droplets passing through the vertical plane, named V1, V2, V3, V4 and $\mathrm{V} 5$, respectively. In addition, at the position of $0.1 \mathrm{~m}$ from wind tunnel bottom, 5 collection lines with $0.1 \mathrm{~m}$ interval, named $\mathrm{H} 1, \mathrm{H} 2, \mathrm{H} 3, \mathrm{H} 4$ and H5, respectively, is placed to detect droplets drift from $2 \mathrm{~m}$ to $7 \mathrm{~m}$ in the horizontal direction. The testbed is shown in Figure 2.

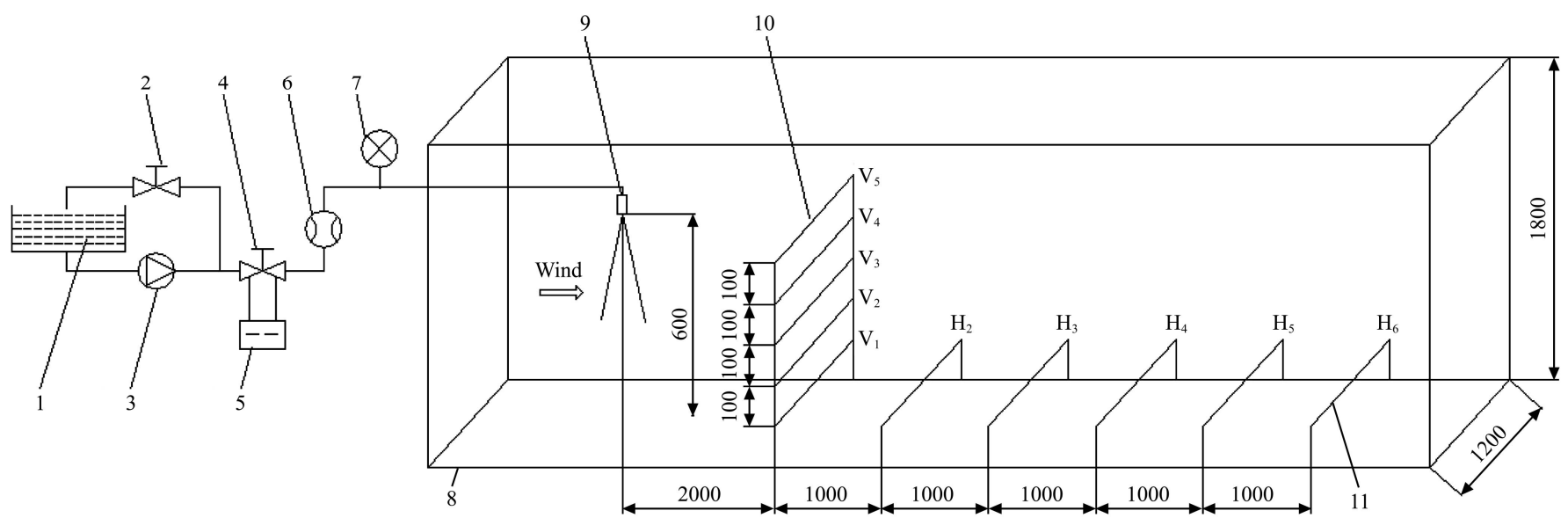

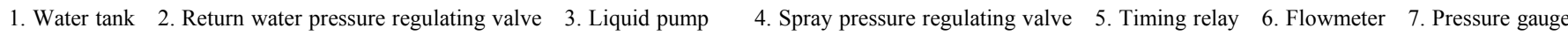
8. Wind tunnel 9. Nozzle 10. Vertical collection rack 11. Horizontal collection rack.

Figure 2 Measurement system of spray deposition distribution

According to ISO/FDIS 22856:2008 Equipment for crop protection -Methods for the laboratory measurement of spray drift - Wind tunnels, the drift index was measured by changing different wind speed, spray pressure and nozzle angle. The flow of the nozzle was controlled by an electromagnetic valve with an electronic timer to ensure that spray time was fixed at $10 \mathrm{~s}$ each 
time. Spray solution was prepared by using fluorescent tracer RHB and water, and the RHB concentration was $0.35 \mathrm{~g} / \mathrm{L}$. After spraying test, we put collection lines into plastic bags, and added $50 \mathrm{~mL}$ deionized water to sufficient wash. Then, the fluorescent tracer content was measured by the calibrated fluorimeter. The testbed layout was shown in Figure 3.

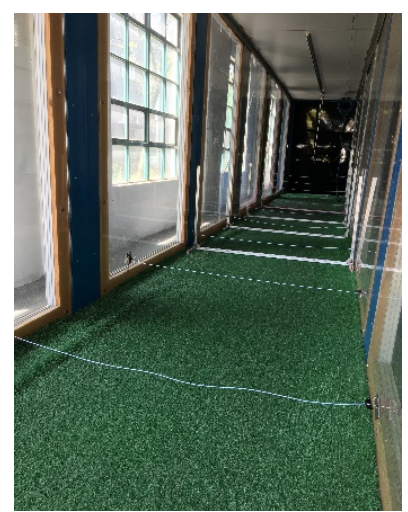

Figure 3 Testbed

\subsubsection{Test design}

In order to study the influence of different spraying parameters on the droplet size distribution, we designed the spray droplets deposition distribution test at different wind speed, spray angle, nozzle angle and spray pressure. The spray angle and nozzle angle were shown in Figure 4. Each test was repeated 3 times, and the average value was taken as the final data.
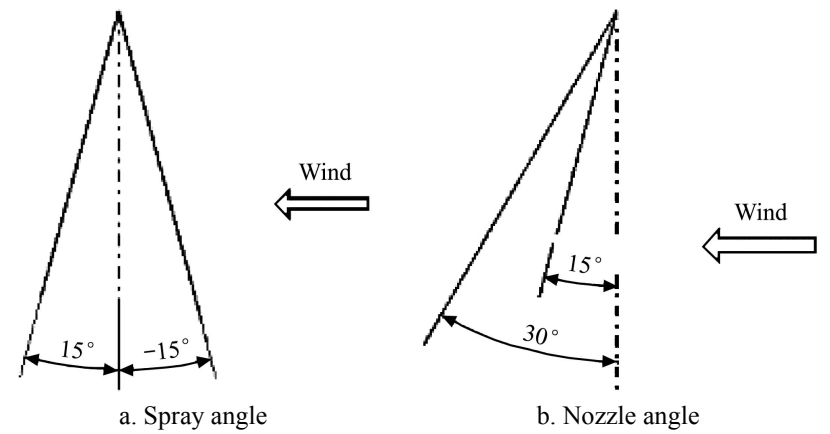

Note: The spray angle is the direction of the spray flow when the observer is at the side of the wind tunnel; the nozzle angle of the nozzle is the direction of the spray flow when the observer is at the top of the wind tunnel.

Figure 4 Nozzle installation diagram

When small aircraft spraying, spray pressure of its fan nozzles is generally set as $0.2-0.4 \mathrm{MPa}$, the wind speed should be chosen within $5 \mathrm{~m} / \mathrm{s}$. There is no literature reported about spray angle and nozzle angle at present, but they may have a certain influence on deposition distribution. So our testing parameters were set as follows.

(1) The influence of spray pressure on deposition distribution: at $0.2 \mathrm{MPa}, 0.3 \mathrm{MPa}$ and $0.4 \mathrm{MPa}$ spray pressure, $3 \mathrm{~m} / \mathrm{s}$ wind speed and $0^{\circ}$ spray angle.

(2) The influence of wind speed on deposition distribution: at $1 \mathrm{~m} / \mathrm{s}, 3 \mathrm{~m} / \mathrm{s}$ and $5 \mathrm{~m} / \mathrm{s}$ wind speed, $0.3 \mathrm{MPa}$ spray pressure and $0^{\circ}$ spray angle.

(3) The influence of spray angle on deposition distribution: at $-15^{\circ}, 0^{\circ}$ and $15^{\circ}$ spray angle, $3 \mathrm{~m} / \mathrm{s}$ wind speed and $0.3 \mathrm{MPa}$ spray pressure.

(4) The influence of nozzle angle on deposition distribution: at $0^{\circ}, 15^{\circ}$ and $30^{\circ}$ nozzle angle, $3 \mathrm{~m} / \mathrm{s}$ wind speed and $0.3 \mathrm{MPa}$ spray pressure.

\subsubsection{Calculation method}

The fluorescent tracer content is measured by the fluorimeter.
Drift index is calculated by using Equation (1) and (2).

$$
\begin{aligned}
P_{i} & =\frac{A_{i}}{K \times 1000} \times 6 \\
D P_{i} & =\frac{P_{i} \times \frac{L}{d}}{P} \times 100 \%
\end{aligned}
$$

where, $P_{i}$ is spray deposition of each collection line for one minute $(\mathrm{L} / \mathrm{min}) ; A_{i}$ is fluorescent tracer content of each collection line $(\mu \mathrm{g} / \mathrm{L}) ; K$ is fluorescent tracer concentration $(0.3 \mathrm{~g} / \mathrm{L}) ; L$ is horizontal interval distance of each collection line $(1000 \mathrm{~mm}) ; d$ is diameter of the collection line $(2 \mathrm{~mm}) ; P$ is spray quantity of the nozzle for one minute $(\mathrm{L} / \mathrm{min}) ; D P$ is drift index, and $D P_{i}$ is drift index of each collection line (\%).

\section{Results and analysis}

\subsection{The influence of spray pressure on droplet size and flow rate}

The spray flow rate increased with the increase of pressure, and the droplet size decreases with the increase of pressure (Table $1)$.

Table 1 Spray flow rate and droplet size at different spray pressure

\begin{tabular}{lccc}
\hline & \multicolumn{3}{c}{ Spray pressure/MPa } \\
\cline { 2 - 4 } & 0.2 & 0.3 & 0.4 \\
\hline Flow rate $/ \mathrm{L} \cdot \mathrm{min}^{-1}$ & 1.165 & 1.426 & 1.715 \\
Droplet size $/ \mu \mathrm{m}$ & 358 & 310 & 290 \\
\hline
\end{tabular}

3.2 Influence of spray pressure on spray drift index

DP of each line decreased with the increase of the distance from the ground along the vertical direction, and decreased with the increase of pressure. DP of V1 was always greatest, and DP of V5 was always minimal at any pressure (Figure 5a). DP of each line decreased with the increase of the distance from the ground along the horizontal direction, and decreases with the increase of pressure. DP of H1 was always greatest, and DP of H6 was always minimal at any pressure (Figure $5 \mathrm{~b}$ ). When spray pressure was $0.2 \mathrm{MPa}$, DPs of V4, V5 and V6 were all 0. It was mainly due to that the increase of spray pressure caused the increase of its own momentum. The penetration performance of droplets was enhanced, and the result was that the upper drift decreased with the increase of pressure in the vertical direction. Most droplets drifted in $2 \mathrm{~m}$ from the nozzle in the horizontal direction and $0.1 \mathrm{~m}$ to $0.3 \mathrm{~m}$ in the vertical direction. The spray droplets became thinner with the increase of pressure, which caused the drift inversely proportional to the spray pressure at interval of $6 \mathrm{~m}$ to $7 \mathrm{~m}$ horizontally.

\subsection{Influence of wind speed on spray drift index}

DP of each line decreased with the increase of the distance from the ground along the vertical direction, and increased with the increase of wind speed. DP of V1 was always greatest, and DP of V5 was always minimal at any wind speed (Figure 6a). DP of each line decreased with the increase of the distance from the ground along the horizontal direction, and increased with the increase of wind speed. DP of H1 was always greatest, and DP of H6 was always minimal at any wind speed (Figure 6b). When wind speed was $1 \mathrm{~m} / \mathrm{s}$ and $3 \mathrm{~m} / \mathrm{s}$, DP s of V4 and V5 were both 0 . When wind speed was $1 \mathrm{~m} / \mathrm{s}$, DPs of $\mathrm{H} 3, \mathrm{H} 4, \mathrm{H} 5$ and $\mathrm{H} 6$ were all 0 . It was the increase of wind speed that resulted in droplets being transported to the non-target area. 


\subsection{Influence of spray angle on spray drift index}

DP of each line decreased with the increase of the distance from the ground along the vertical direction. DP of V1 was always greatest, and DP of V5 was always minimal at any spray angle (Figure 7a). DP of each line decreases with the increase of the distance from the ground along the horizontal direction. DP of H1 was always greatest, and DP of H6 was always minimal at any spray angle (Figure $7 \mathrm{~b}$ ). When spray angle was $0^{\circ}$, DPs of both vertical and horizontal direction were larger than other angles. When spray angle was $-15^{\circ}$, DPs of V4, V5 and H6 were all 0 . In the wind direction, the windward area of spray flow increased, when the nozzle front and rear tilted. As a result, the effect of wind speed on spray flow was weakened, and the target deposition increased.

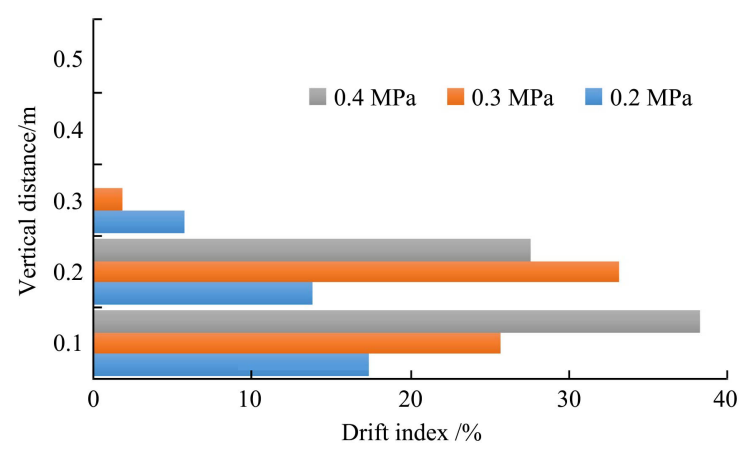

a. Vertical direction

Note: Wind speed is $3 \mathrm{~m} / \mathrm{s}$, spray angle is $0^{\circ}$, spray medium is water.

Figure 5 Drift index in the vertical and horizontal direction in different spray directions.

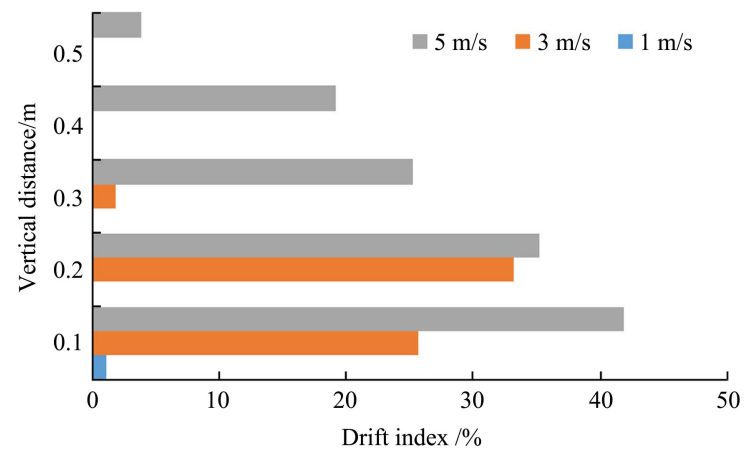

a. Vertical direction

Note: Spray pressure is $0.3 \mathrm{MPa}$, spray angle is $0^{\circ}$, spray medium is water.

Figure 6 Drift index in the vertical and horizontal direction at different wind speed



a. Vertical direction

Note: Wind speed is $3 \mathrm{~m} / \mathrm{s}$, spray pressure is $0.3 \mathrm{MPa}$, spray medium is water



b. Horizontal direction

\subsection{Influence of nozzle angle on spray drift index}

DP of each line decreased with the increase of the distance from the ground along the vertical direction. DP of V1 was always greatest, and DP of V5 was always minimal at any nozzle angle (Figure 8a). DP of each line decreased with the increase of the distance from the ground along the horizontal direction. DP of $\mathrm{H} 1$ was always greatest, and DP of H6 was always minimal at any nozzle angle (Figure 8b). DPs of V4, V5 and H6 were all 0 at any nozzle angle, and DPs were similar between V1 and H2. The spray surface was changed by reason of different nozzle angle. Under the action of wind speed, the collision probability increased to make the droplets larger. When nozzle angle was $0^{\circ}$, DP was greatest, but the spraying swath was widest.

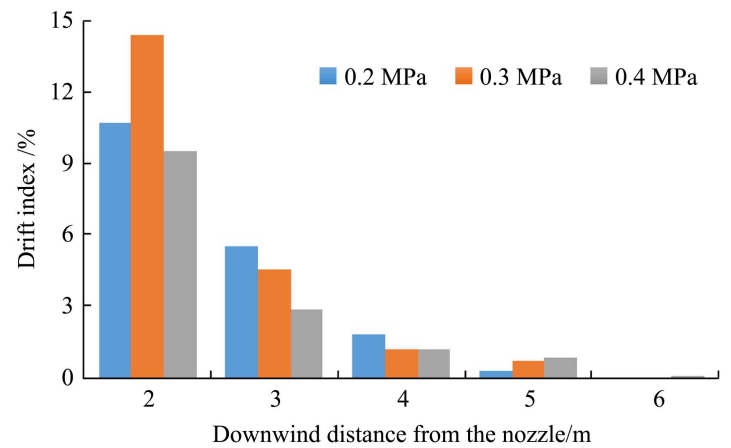

b. Horizontal direction

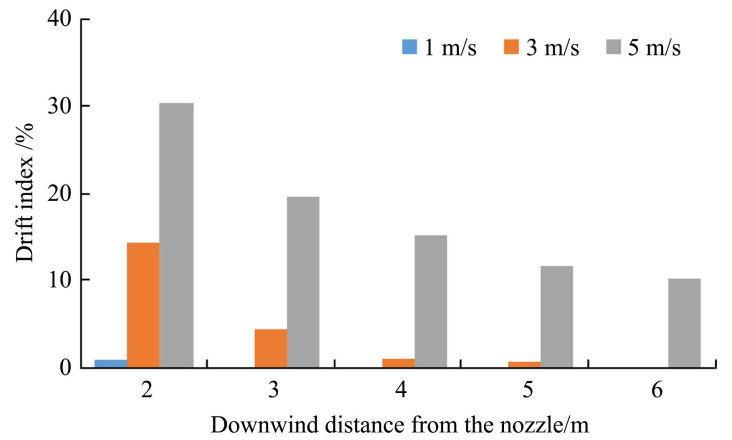

b. Horizontal direction

Figure 7 Drift index in vertical and horizontal direction in different spray direction 


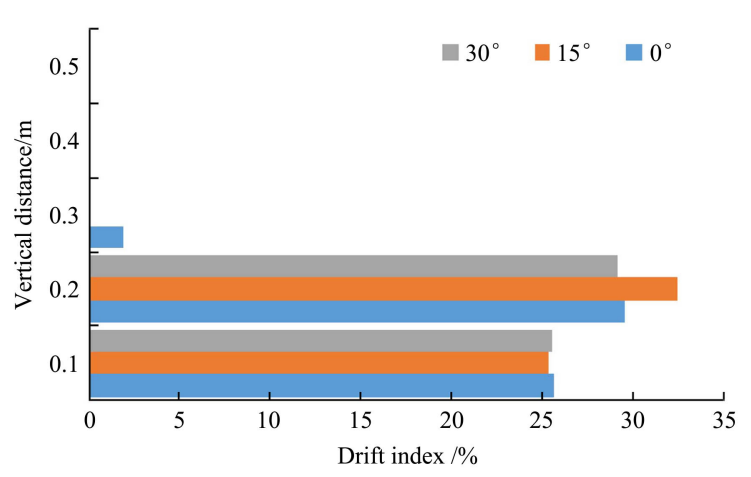

a. Vertical direction

Note: Wind speed is $3 \mathrm{~m} / \mathrm{s}$, spray pressure is $0.3 \mathrm{MPa}$, spray medium is water.

Figure 8 Drift index in vertical and horizontal direction in different nozzle direction

\section{Conclusions}

A spray drift index experiment was conducted with the LURMARK-04F80 nozzle in a wind tunnel at different wind speed, spray pressure, spray angle, and nozzle angle, and provided optimized operation parameter for aerial nozzle and droplet drift reduction.

(1) Drift index decreased with vertical distance increasing. Drift index attained greatest at $0.1 \mathrm{~m}$ height from the ground. Drift index decreased with horizontal distance increasing. Drift index attained greatest at $2.0 \mathrm{~m}$ horizontal distance from the nozzle with any nozzle angle.

(2) Spray pressure and wind speed had great influence on the drift parameter. Spray droplet drift still existed $7 \mathrm{~m}$ distant from the nozzle when spray pressure attained $0.4 \mathrm{MPa}$, wind speed attained $3 \mathrm{~m} / \mathrm{s}$ and spray angle was $0^{\circ}$, or when wind speed attained $5 \mathrm{~m} / \mathrm{s}$, spray pressure attained $0.3 \mathrm{MPa}$ and spray angle was $0^{\circ}$.

(3) Drift index in the vertical and the horizontal direction when the spray angle is $0^{\circ}$ was higher than that of the other spray angles. When spray distance attained $4 \mathrm{~m}$ and nozzle angle attained $0^{\circ}$, the drift index was higher than that of other nozzle angles.

(4) To reduce the droplet drift when the wind speed attained $5 \mathrm{~m} / \mathrm{s}$, spray operation creating droplet size should be adopted and the spray angle should be adjusted.

\section{Acknowledgements}

This research was supported and funded by The National Key Research and Development Program of China (No. 2017YFD0700905) and Basic Scientific Research Expense of Chinese Academy of Agricultural Sciences (No. Y2017PT32).

\section{[References]}

[1] Zhou Z Y, Zang Y, Luo X W, et al. Technology innovation development strategy on agricultural aviation industry for plant protection in China. Transactions of the CSAE, 2013, 29(24): 1-10. doi: 10.3969/ j.issn.1002-6819.2013.24.001. (in Chinese)

[2] Xue X Y, Lan Y B. Agricultural aviation applications in USA. Transactions of the CSAM, 2013, 44(5): 194-201. doi: $10.6041 / \mathrm{j}$. issn.1000-1298.2013.05.034. (in Chinese)

[3] Zhang Y L, Lan Y B, Bradley K F, et al. Development of aerial electrostatic spraying systems in the United States and applications in China. Transactions of the CSAE, 2016, 32(10): 1-7. doi: 10.11975/ j.issn.1002-6819.2016.10.001. (in Chinese)

[4] Tu Y Q. Pesticide formulation and dose transfer. Chinese Journal of Pesticide Science, 1999, 1(1): 1-6.

[5] Liu X J, Zhou H P, Zheng J Q. Research advances of the technologies for spray drift control of pesticide application. Transactions of the CSAE,

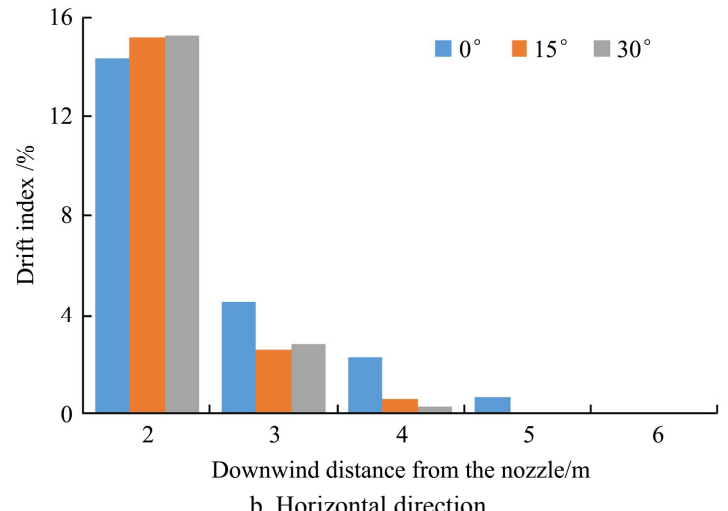

2005, 21(1): 186-190. doi: 10.3321/j.issn:1002-6819.2005.01.042. (in Chinese)

[6] Wang X N, He X K, Wang C L, et al. Spray drift characteristics of fuel powered single-rotor UAV for plant protection. Transactions of the CSAE, 2017, 33(1): 117-123. doi 10.11975/j.issn.1002-6819.2017.01.016. (in Chinese)

[7] Hewitt A J. Droplet size spectra classification categories in aerial application scenarios. Crop Protection, 2008, 27(9): 1284-1288. doi: 10.1016/j.cropro.2008.03.010

[8] Qin W C, Xue X Y, Zhou L X, et al. Effects of spraying parameters of unmanned aerial vehicle on droplets deposition distribution of maize canopies. Transactions of the CSAE, 2014, 30(5): 50-56. doi: 10.3969/j.issn.1002-6819.2014.05.007. (in Chinese)

[9] FRITZ B K. Role of atmospheric stability in drift and deposition of aerially applied sprays-preliminary results. // 2004 ASAE Annual Meeting ASAE Paper 041031,2004. doi:10.13031/2013.16134

[10] Huang Y B, Thomson S J, Hoffmann W C, et al. Development and prospect of unmanned aerial vehicle technologies for agricultural production management. International Journal of Agricultural \& Biological Engineering, 2013, 6(3): 1-10. doi: 10.3965/j.jjabe.20130603. 001

[11] Emilia H, Arnoldus W. P. Vermeer. Spray drift review: The extent to which a formulation can contribute to spray drift reduction. Crop Protection, 2013, 44:75-83. doi: 10.1016/j.cropro.2012.10.020

[12] Yang F B, Xue X Y, Cai C, Zhou Q Q. Effect of down wash airflow in hover on droplet motion law for multi-rotor unmanned plant protection machine. Transactions of the CSAE, 2018, 34(2): 64-73. doi: 10.11975/j.issn.1002-6819.2018.02.009. (in Chinese)

[13] CHEN S D, LAN Y B, BRADLEY K F, et al. Effect of Wind Field below Rotor on Distribution of Aerial Spraying Droplet Deposition by Using Multi-rotor UAV. Transactions of the CSAM, 2017, 48(08): 105-113. doi: 10.6041/j.issn.1000-1298.2017. 08.011. (in Chinese)

[14] Wen S, Lan Y B, Zhang J T, et al. Analysis and experiment on atomization characteristics of ultra-low volume swirl nozzle for agricultural unmanned aviation vehicle. Transactions of the CSAE, 2016, 32(20): 85-93. doi: 10.11975/j.issn.1002-6819.2016.20.011. (in Chinese)

[15] Wang X N, He X K, Song J L, et al. Effect of adjuvant types and concentration on spray drift potential of different nozzles. Transactions of the CSAE, 2015, 31(22): 49-55. doi: 10.11975/j.issn.1002-6819.2015. 22.007. (in Chinese)

[16] Fritz B. K, Hoffmann W. C, Martin D. E, et al. Aerial application methods for increasing spray deposition on Wheat Heads. American Society of Agricultural and Biological Engineers, 2007, 23(6): 709-715. doi: $10.13031 / 2013.20453$

[17] Nuyttens D, Taylor W A, Schampheleire M D, et al. Influence of nozzle type and size on drift potential by means of different wind tunnel evaluation methods. Biosystems Engineering, 2009, 103(3): 271-280. doi: 10.1016/j.biosystemseng.2009.04.001

[18] Herbst A. A method to determine spray drift potential from nozzles and its link to buffer zone restrictions[C]//ASAE paper 011047. 2001. doi: $10.13031 / 2013.7333$

[19] Geng B, Kazuhiro N, Tomomichi M. K, Sumihiko M, Shintaroh O, Yosuke K, Ken-ichi T \& Yan H J. Characteristics and classification of Japanese nozzles based on relative spray drift potential. Crop Protection, 2013, 46: 
88-93. doi: 10.1016/j.cropro.2012.12.017

[20] Teske M E, Bowers J F, Rafferty J E, et al. FSCBG: An aerial spray dispersion model for predicting the fate of released material behind aircraft. Environmental Toxicology and Chemisty, 1993, 12(3): 453-464. doi: 10.1002/etc.5620120307

[21] Teske M E, Thistle H W. Aerial application model extension into the far field. Biosystems Engineering, 2004, 89 (1): 29-36. doi: 10.1016/ j.biosystemseng.2004.06.010

[22] Nuyttens D, De Schampheleire M, Baetens K, et al. The influence of operator-controlled variables on spray drift from field crop sprayers. Transactions of the ASABE, 2007(4): 1129-1140.

[23] Li B H, Wang G Q, Li X J, et al. Determination of indoor simulation of pesticide drift. Journal of Hebei Agricultural Sciences, 2006, 10(2): 43-46. doi: 10.16318/j.cnki.hbnykx.2006.02.011. (in Chinese)
[24] Qi L J, Hu J R, Shi Y, et al. Correlative analysis of drift and spray parameters. Transactions of the CSAE, 2004, 20(5): 122-125. doi: 10.3321/j.issn:1002-6819.2004.05.026. (in Chinese)

[25] Zhang H C, Gary Dorr, Zheng J Q, et al. Wind tunnel experiment and regression model for spray drift. Transactions of the CSAE, 2015, 31(3): 94-100. doi: 10.3969/j.issn.1002-6819.2015.03.013. (in Chinese)

[26] Zhang H C, Dorr G, Zheng J Q, et al. Wind tunnel experiment of influence on droplet size distribution of flat fan nozzles. Transactions of the CSAM, 2012, 43(06): 53-57. doi: 10.6041/j.issn.1000-1298.2012.06.010. (in Chinese)

[27] Ding Suming, Xue X Y, Lan Y B, et al. Design and experiment of NJS-1 type open-circuit closed wind tunnel for plant protection. Transactions of the CSAE, 2015, 31(4): 76-84. doi: 10.3969/j.issn.1002-6819.2015.04.011. (in Chinese) 